AperTO - Archivio Istituzionale Open Access dell'Università di Torino

\title{
Citizenship as a connecting factor in private international law for family matters
}

\section{This is the author's manuscript}

Original Citation:

Availability:

This version is available http://hdl.handle.net/2318/141680

since

Terms of use:

Open Access

Anyone can freely access the full text of works made available as "Open Access". Works made available under a Creative Commons license can be used according to the terms and conditions of said license. Use of all other works requires consent of the right holder (author or publisher) if not exempted from copyright protection by the applicable law. 


\section{Citizenship as a connecting factor in private international law for family matters}

Madrid, $12^{\text {th }}$ September 2013

* Marco Raiteri

Good morning everyone.

I would first like to extend my heartfelt thanks to the organisers and scientific committee of this Conference for giving me this wonderful opportunity to speak to you all at these seminars on a topic that is particularly dear to me and also the main subject of my Ph.D. thesis, which I will tell you about shortly.

The institute of citizenship was traditionally conceived as an inclusion or exclusion factor in the relationship between citizens and foreigners with regard to entitlement to rights. It plays a vital historical role in family matters and, more generally, in matters relating to the civil status of people. This arises out of the idea that a national court is best suited to rule on such notions for reasons of cultural or spiritual affinity.

In Italy, the criterion of citizenship was rigorously and forcefully advocated by Pasquale Stanislao Mancini from the middle of the nineteenth century. Mancini directly inspired the first uniform code of law with regard to both the range of jurisdiction and determination of applicable law by Italian courts and the Italian legislature has always remained true to his teachings. Not even the study Committee on Law 218/1995 gave any serious consideration to reviewing this criterion.

The criterion of citizenship has therefore held firm as a fundamental factor even though certain far from irrelevant changes have been introduced in practice. In procedural terms, a defendant's Italian citizenship is not in itself a general entitlement to jurisdiction (compare Article 3, paragraph I of the 1995 law with Article 4 of the 1940 Code of Civil Procedure) yet still retains an extremely important role in special rules covering the many issues involved in personal status, as we will see shortly. Subsidiary criteria have been introduced in terms of the applicable law: examples include relationships between spouses of different nationalities, which are now subject to the law of 
the State where they mainly conduct their married life. Several doctrinal questions have been raised over whether a more comprehensive reworking is justified based on the current situation, experience built up on the basis of the Brussels and Rome Conventions and European Union actions on private international law.

With this in mind, a review of our adherence to Mancini's principals is not only prompted by the European Union experience - on which subject we need only mention that "any discrimination on grounds of nationality shall be prohibited" (Article 18 TFUE) - but also the extensive development of national laws on citizenship, beginning with Italian law. Compared to many States, citizenship is losing its ability to express an individual's emphatic membership of the community of people who make up a State's social base. In the not-so-distant past, the vast majority of national lawmakers aimed to avoid situations of dual nationality. The Council of Europe Convention - 6 May 1963 - on the Reduction of Cases of Multiple Nationality and Military Obligations in Cases of Multiple Nationality was a clear expression of this approach. For present purposes, this Convention surprisingly did not undergo radical changes in accordance with the second Protocol of Amendment, opened for signature in Strasbourg on 2 February 1993 and ratified by Italy. As in the law on Italian citizenship, many foreign laws provided that, on marriage, a wife should take on her husband's nationality, losing her own original nationality and only the father was able to pass on his nationality to their children.

Today the need to respect equality between men and women has led to a radical about-turn. Many legal systems, beginning with the Italian system, facilitate the passing-on of nationality to a foreign spouse by either husband or wife and allow both the father and the mother to pass on their nationality to their children. This is done regardless of any social or political integration.

It must also be said that Italy is no longer the country of great emigration that it used to be in Mancini's time and remained for many years after. Now exactly the opposite is true and in recent decades it has become the destination of significant flows of migrants who flock in from States with very different cultures to our own. This means that Italian courts are often faced with difficulties that can only be overcome by stretching public order to its limits. Even in the knowledge that loyalty to Mancini, in other words the 
criterion of citizenship, can be more respectful to the original cultural identity of foreigners when faced with the problem of migration, the majority doctrine nevertheless inclined towards an idea of "betrayal", not merely to bring 'forum' into line with 'jus', and hence the application of Italian substantive law in our courts, but also because this would make it possible to follow the prevailing attitude in uniform international private law. As early as the Hague Convention of 1902 on the guardianship of infants, the criterion of habitual residence appeared as an antithesis to the criterion of citizenship, replacing the more traditional criterion of domicile, upon the suggestion of the Italian delegate Augusto Pierantoni, who was incidentally Mancini's son-in-law. The connecting factor of habitual residence as it relates to different individuals and situations is now used by EU Regulations of 2007 and 2008 concerning the law applicable to non-contractual and contractual obligations respectively and is also destined to play an essential role with regard to the law governing succession due to death.

The crux of the problem is therefore the relationship between a concept that relates mainly to the political matrix of State - citizenship - and connecting factors that lay more emphasis on an individual's proximity, in a topographical sense, to the States emanating the rules applicable to the legal situations involved. The EU concept of habitual residence is different from that of residence defined by paragraph II of Article 43 of the Italian Civil Code which locates it "in the place where the person has their regular abode" - and is essentially closer to the notion of domicile, which paragraph I of the same Article 43 states is the main place where a person "takes care of his affairs and interests".

It would therefore be useful to update Italian rules of international private law to replace the connecting factor of citizenship with that of habitual residence, in line with European Union policies. This would align Italian international private law with uniform systems of international private law that are already in force or in the process of adoption, depending on areas of interest.

Under EU individual and family law, the nationality of spouses has retained an entirely marginal role as a connecting factor.

Only two of the seven criteria of jurisdiction laid down in Article 3 of Regulation No 2201/2003 actually refer to nationality. In one case (Article 
3(a), final indent), nationality coincides with habitual residence in determining jurisdiction. In the other case, nationality performs the independent function of identifying legal entitlement, but this is possible only where it is common between the spouses.

In other words, the nationality of only one of the two spouses no longer makes it possible to identify any genuine connection with the territory of a Member State, unless it is reinforced by an additional territorial factor (habitual residence) or is specifically common to both spouses. The earlier Community system and now the European Union system therefore consecrated the transition from a concept of nationality as an element that was absolute and sufficient for the identification of jurisdiction to a concept of qualified nationality, in other words backed by an additional element capable of guaranteeing the authenticity of the identified connection.

Over and above these cases, nationality in its classical sense retains a residual area of application in cases not covered by the courts of any EU Member State where it is therefore necessary for a respondent to avail himself - as provided for in Article 7 of Regulation 2201/2003 - of national exorbitant jurisdictions.

As these examples show, citizenship has cast off its mantle as a criterion of direct competence but still has a direct impact on the sphere of jurisdiction, guaranteeing Member State nationals a privileged position. More specifically, "EU" citizenship - in other words nationality of a Member State - now acts as a privileged jurisdictional element, both in a positive sense - by ensuring national courts can be used by citizens of other Member States - and also in a negative sense - by limiting the scope of national exorbitant jurisdictions to non-EU citizens or those who do not have their habitual residence within the EU. European Union citizenship has also been at the heart of another recent judgement handed down by the Court of Justice, in the Zambrano case.

According to the spirit of EU law, common nationality was intended to guarantee a genuine and real connection with the situation, avoiding the creation of exorbitant jurisdictions associated with the citizenship of only one of the spouses. Even common nationality does not actually always guarantee a sufficiently well-defined connection since it could well be the case that spouses of the same nationality have stably and permanently relocated their 
married life to a different country and thus most of the elements of the case in point will relate to this State.

The choice of the EU lawmaker is therefore aimed at providing a "supplementary" EU jurisdiction if the main jurisdictions based on the habitual residence of the spouses (or one of the spouses) are insufficient to locate the jurisdiction within EU territory. For example, if a couple of EU citizens of the same nationality who have lived out their entire married life in a non-EU state, their EU citizenship acts as an "extreme" criterion that is used to reclaim and incorporate certain situations that would otherwise not be destined to have any connection with the EU within the scope of EU rules. This approach opens up the possibility of one or both spouses petitioning their own national courts for the dissolution of their marriage when they return to their own States after the marriage breakdown.

One such example is provided by a case recently ruled on by the Cour de Cassation, which held that the French court had jurisdiction based on Article $3(b)$, even if all elements of the marriage were actually located in a different Country.

Regulation 2201/2003 does not specify what happens if the spouses hold several nationalities or even if they hold more than one nationality in common. The rule of conflict between the different nationalities should therefore be sought in the national rules of conflict. In the case of the Italian legal system, this should lead to the application of Article 19, second paragraph of Law $218 / 1995$ which, in the event of conflict between nationalities, states that the one with a closer connection with the case should take precedence except in the case of conflict with Italian citizenship, in which case the latter takes precedence. In both cases, the application of Article 19, second paragraph is, however, at odds with the aim of EU law: Italian citizenship taking precedence over another EU citizenship could be at odds with the general prohibition imposed by EU law on discriminating on the basis of nationality and could ultimately be detrimental to the aim of uniform application of EU law. This would happen, for example, if two spouses were both Italian nationals and also had the nationality of another EU country. In this situation, the two "European" nationalities should clearly be seen as exactly equal and the national court must assess them as two mutually exclusive independent 
jurisdictional entitlements with equal dignity. Cases of dual nationality are bound to increase as European society develops. The Court of Justice has ruled several times on this point, departing from the international principle of "effective" nationality. In order to exercise the freedom guaranteed by the Treaty, the Court states that the legislation of a Member State may not limit the effects of granting citizenship of another Member State by imposing an additional condition for recognition of that citizenship (as occurred in the Micheletti and Garcia Avello judgements).

This principle has also been clarified recently with reference to international private law, in a case regarding spouses who had both Hungarian and French citizenship and had filed two separate petitions for divorce, one with a Hungarian court and another with a French court: judgement of 16 July 2009, in the Hadadi case. In a case such as this, where there is a "perfect" conflict between two legal titles, the EU courts clarified that the "objective" rule of prevention applies, which in practice gives the jurisdiction to the first court seised.

A different situation could apply in the case of conflict between an EU nationality and a non-EU nationality: in this case, the need to avoid situations of discrimination under EU law would no longer apply and the automatic precedence of national citizenship within the EU (as in the case of Article 19, second paragraph, final indent of Law 218/1995) could well be justified by the aim of ensuring the application of EU law as opposed to national exorbitant jurisdictions.

In the same way, Article 19, second paragraph, first indent would not be applicable. As already stated, this establishes the precedence of the nationality that has a closer connection with the situation: the practical application of this subsidiary criteria would lead to a substantial distortion of the hierarchy between the legal titles referred to in Article 3 of Regulation No 2201/2003. More specifically, this would mean relinquishing the criterion of nationality to effectively give hierarchical precedence to the criterion of habitual residence. In other words, in the economy of the judicial system outlined by the EU legislature, nationality has an absolute value that cannot be adapted in the light of the actual situation. The solution of literally interpreting Article 3(b) of Regulation No 2201/2003 is undoubtedly the most 
appropriate, including in terms of predictability of the jurisdiction. If we interpret the criterion of nationality, avoiding any reference to rules of national conflict, but purely and simply applying the jurisdiction of the State of which both spouses are nationals, there is no doubt that the spouses will reasonably be able to predict the court to which they should submit their petition for dissolution of the marriage. This solution also offers the advantage of observing the principles laid down in Article 3(b) and, in general, the purpose of Regulation No 2201/2003 which, as already stated, is to facilitate dissolution of the marriage and allow the spouses to achieve this result in the simplest possible manner.

Otherwise there would be a risk of making the application of EU rules subject to supplementary national criteria that would in practice bring about a different effect, which could potentially be at odds with the principles of EU law.

We are nevertheless bound to ask whether the Court of Justice would reach the same conclusion as in the Hadadi case if the applicable law were observed: in other words, if the court hearing the case did not have to treat the laws of both the States of which the parties are nationals as though they were on the same level. Regulation No 2201/2003 does not contain provisions on the applicable law. The Proposal for a Regulation of 17 July 2006, revising the Brussels // bis Regulation, states with regard to the choice of applicable law that this should be dictated by compliance with the principle of "proximity". In the absence of choice, the legislature identifies successive criteria that recall "the law of the State of the habitual common residence of the spouses, or failing that of their last habitual residence if one of them still resides there or failing that of which both the spouses are nationals or.... failing that of the habitual residence of the defendant" (Article 20b). In the case of dual citizenship, the spouses could therefore choose to apply to the court of one of the two States of which they are nationals and to establish the law of another State of which they are nationals as the applicable law. In this case, following the reasoning of the Court, we cannot fail to conclude that the court applied to could not deny the application of the law of another Member State merely because the spouses had lived for many years in the State where the court is located. The independence of the parties takes precedence, provided the guidelines laid down in the Regulation are complied with. Greater 
independence of the parties and the introduction of criteria such as habitual residence will certainly reduce problems associated with cases of dual citizenship.

The recent "Rome III" Regulation (1259/2010) is certainly in line with the approach outlined by Regulation No 2201/2003 and also touched on by the enactment of Regulation No 4/2009 on maintenance obligations. This Regulation establishes reinforced cooperation within the scope of the law applicable to divorce and personal separation and is based on the acknowledgement that the spouses are bound to choose a jurisdiction that has a strong connection with their marriage. According to the Regulation (Article 8), this connection mainly consists of the common habitual residence of the spouses or the last habitual residence of the spouses if one of them still resides there, followed by the citizenship of one of the spouses and ultimately the 'lex fori'. If no agreement is reached, the applicable law is determined on the basis of a set of objective connecting factors intended to ensure that the process of weakening or dissolving the bond is governed by a legal system with which the spouses have a close connection. In general, the Regulation gives precedence to the criterion of the habitual residence of the spouses at the time when the petition was filed with the judicial authority. The precedence accorded to the residence of the spouses over their nationalities is motivated by the advantages that this connecting factor offers over the criterion of their nationality.

To conclude, the criterion of citizenship is losing its former strength and becoming an alternative or even a subsidiary criterion, giving way to other criteria that are more relevant to the current situation. Despite this, citizenship is not disappearing altogether: it now occupies a subordinate position to meet the unique needs of a diverse European society.

Thank you for your attention. 